
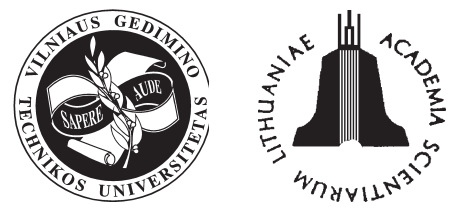

ISSN 1648-4142 TRANSPORT

http:/www.vtu.lt/english/editions

\title{
ROAD IDENTIFICATION FOR ITS-INTEGRATED SYSTEMS OF AUTOMOTIVE ACTIVE SAFETY
}

\author{
Valentin Ivanov, Barys Shyrokau, Vladzimir Siakhovich \\ Belarusian National Technical University, 65 F. Skaryny Ave., 220013 Minsk, Belarus \\ E-mail:valgeoiva@netscape.net
}

Received 2004-12-20; accepted 2005-01-25

\begin{abstract}
The paper discusses several aspects of active safety control for automotive application. Particular emphasis is placed on the fuzzy logic determination of friction properties of a tyre-road contact. An example of vehicle control systems equipped with off-board sensors of road roughness, temperature, moisture and rain intensity demonstrates the implementation of this approach. The paper proposes conceptual solutions for preventive active safety control applied to vehicles which are integrated in an intelligent transportation system.
\end{abstract}

Keywords: antilock braking systems, automotive control, fuzzy systems; fuzzy modeling, tyres

\section{Introduction}

The active safety is an important attribute of an automobile and characterizes its ability to reduce the probability of dangerous driving situation. A number of automotive systems support the active safety: antilock braking systems (ABS), traction control systems and vehicle dynamics control systems. The determinative and most critical factors of active safety are connected with the processes of tyre-road interaction which can be assessed through the dependence between specific contact forces and wheel slip (Fig 1). The problem facing the majority of active safety systems is to avoid the wheel rolling in the post-extreme area of $\mu(s)$-curves. Although the present-day systems are powerful enough to cope with this task, the potential for safety enhancement remains untapped.

New solutions in this sphere can be arisen with the combined application of intelligent control methods and the technique for Intelligent Transportation Systems (ITS). By this means the active safety system gains an opportunity to build a preventive and predictable procedure of vehicle control using both internal and external informational area. To realize this kind of control process it is essential to know the tyreroad friction properties at every instant of vehicle motion. The problem under discussion can be solved using computational and hardware-based approaches.

\section{Problem of road identification in active safety con- trol}

For computational identification of the road properties at different time researchers proposed neural networks [17, 18], tribological models [3], disturbance observer [14, 26], models based on Kalman filter $[6,19,20]$, various dynamic models $[5,8,25]$.

Analytic definition of tyre-road contact parameters in algorithms of real automotive control systems is limited by high requirements for operating speed especially during the braking process. The response time of brake drive and hysteresis losses in brake gears also place serious limitation on these methods.

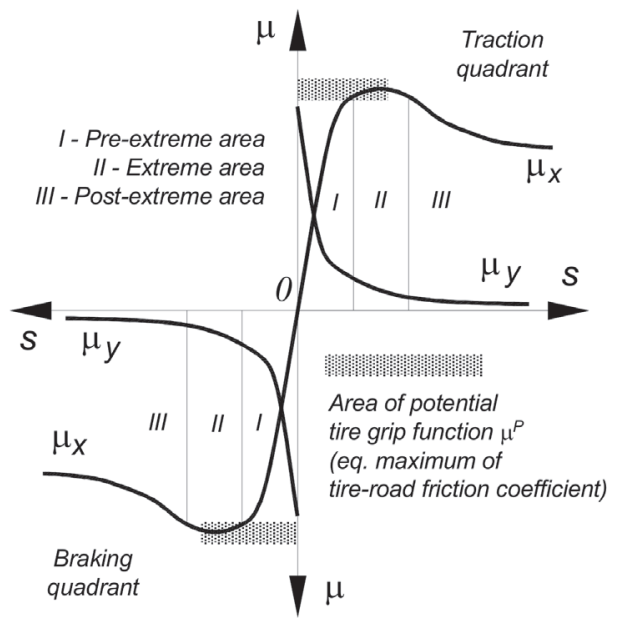

Fig 1. The dependence of specific tyre forces upon wheel Slip: $\mu_{x}$ - coefficient of longitudinal tyre force; $\mu_{y}-$ coefficient of lateral tyre force; $s$ - wheel slip

On the other hand only analytical methods cannot be represented as universal approach for the iden- 
tification of road properties because of "chaotic" nature of a tyre-road contact. The work [22] demonstrated that two tyres with equal potential functions in statics could reveal the differing kinematic functions in dynamics.

The hardware-based definition of tyre-road contact parameters can be also realized in various ways, for example, with the detecting devices scanning the road surface profile (microwave spectrometers, Doppler sensors) and tyre deformation sensors. In addition, the transducers of reactive force or reactive moment are well known. These devices can be installed in vehicle elements that receive the forces within the tyre-road contact (suspension, brake gear support). In spite of intensive investigations of this problem [15, 16, 23], a number of constructional factors restrain the utilization of such devices. Nonetheless, good prospects in this area can be found with ITS-technologies that expand information field of automotive control systems by the application of various off-board sensors.

The examination of up-to-date tendencies in the active safety control is a good reason to solve the identification problem for road conditions through the combined adaptation of computational and hardwarebased methods. The following chapters discuss a variant of corresponding control strategy.

\section{Fuzzy logic method of road identification for ac- tive safety system with off-board sensors}

A coefficient of friction between a tyre and a road surface depends on many factors that are specified both by the properties of a vehicle and by the tribological properties of a contact patch. The most considerable factors are:

- Texture of road surface

- Micro- and macroprofile of road surface

- Normal force acting on a tyre-road contact

- Velocity of a vehicle during performed maneuver

In a general way algorithms of active safety systems are tuned to a dry, wet (as function of water film in a contact patch) or ice-covered road surface. The wide dispersion of extremum of $\mu_{x}(s)$-curve for specific conditions prohibits the use of precise analytical models in the control algorithm. Empirical models (for example, the well-known Magic Formula tyre or Pacejka tyre model) are also limited by the processing speed of hardware components. In this context the acceptable alternative solution calls for the fuzzy logic methods. This approach has well-established application in active safety systems for the calculation of vehicle velocity.
The following limitation should be made for further discussion: the paper considers the motion of a vehicle as an ITS-object on the road equipped with the detection system involving the sensors for environmental temperature, moisture and intensity of atmospheric precipitation (rain intensity sensor) as well as road surface scanner. The indicated information can be transmitted to the vehicle by the way of dedicated short-range communication such as wireless LAN technology, IEEE 802.11 protocol [7].

The proposed method is based on two fuzzy controllers arbitrarily called a roughness controller and an environmental controller. The roughness controller uses the scanner-produced values for the surface micro- and macroprofile in a current road section as input variables. Output variable represents certain basic value of friction coefficient $\mu_{\text {base, }}$ which is the characteristic of standard road surface texture (Fig 2). The rules in a computation block were deduced from the information based on the works [2,4]. The environmental controller corrects the basic value of a friction coefficient taking into account the ambient air temperature, moisture and rain intensity. The correction result is the new value of friction coefficient $\mu_{\text {env }}$.
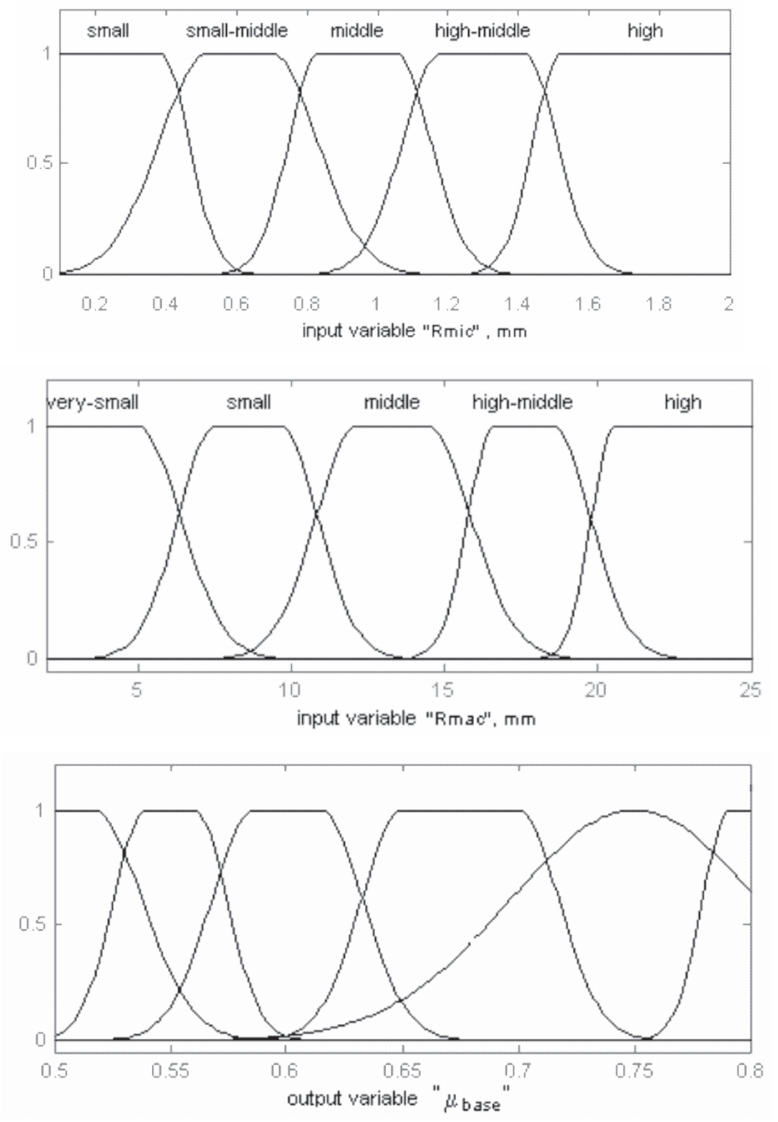

Fig 2. The input and output variables of roughness controller.

Road type for $\mu_{\text {base }}$-variable: 1 - wet concrete; 2 - mixed cement/concrete; 3 - rolled asphalt concrete; 4 - asphalt; 5 dry asphalt concrete; 6 - modificated dry asphalt concrete 
The corresponding description of input and output variables is given in Fig 3. The rules for this controller have been formed according to the statistical observations of weather conditions.

Both controllers are combined into a single logical block which calculates the identified value of a tyre-road friction coefficient $\mu^{p}$ with the following algorithm: value;

IF $1 / 2 \mu_{\text {env }}-\mu_{\text {base }} 1 / 2<0.1$ THEN $\mu^{p}$ is simple average

IF $\left(\mu_{\text {env }}-\mu_{\text {base }}\right)>0.1$ THEN $\mu^{p}=\mu_{\text {base }}$;

$\operatorname{IF}\left(\mu_{\text {env }}-\mu_{\text {base }}\right)<-0.1$ THEN $\mu^{p}=\mu_{\text {env }}$.

By this procedure the identification algorithm has been simulated in MATLAB software (Fig 4). Examples of simulated results are shown in Figs 5 and 6. The analysis of these results allows to make the conclusion that the obtained values of a friction coefficient can be adequately related to the statistical data for real road conditions [9]. The Table gives examples of the obtained friction values.
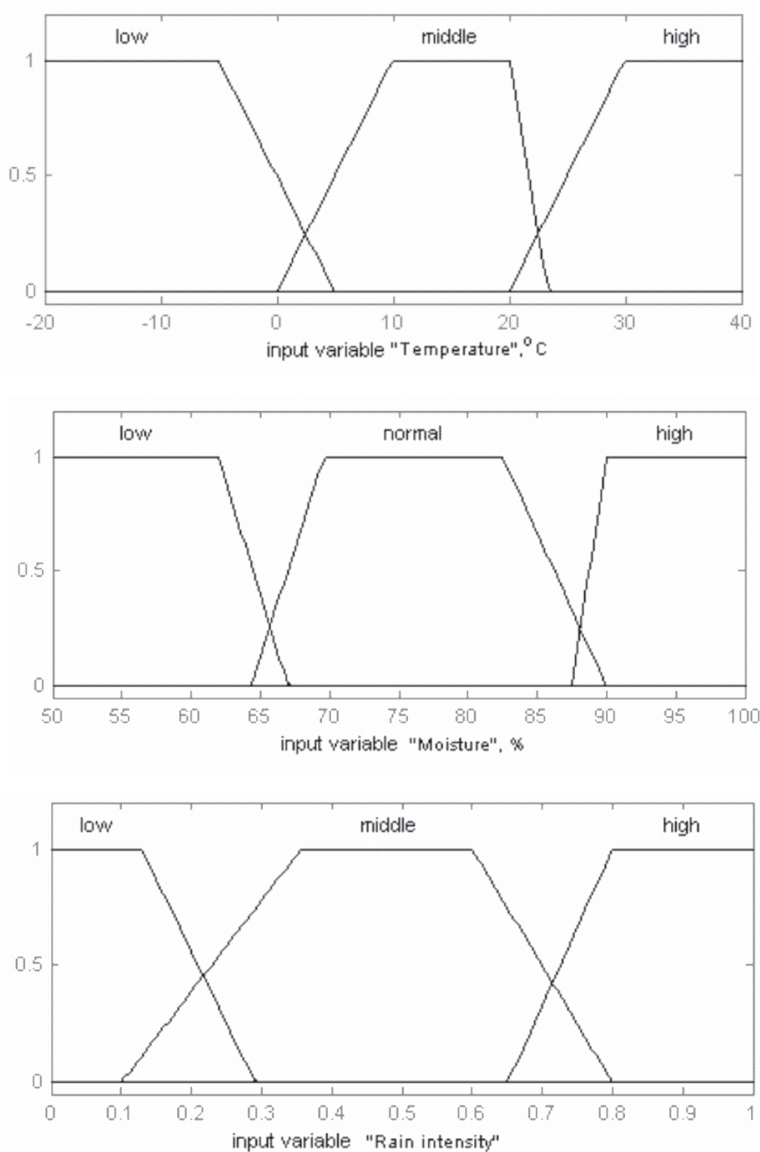

Fig 3. The input and output variables of an environmental controller

(Rain Intensity at 1 is equal to $10 \mathrm{~mm} / \mathrm{min}$ )

Legend for $\mu_{\text {en }}$ - variable: 1 - ice, low temperature of ice surface $\left(<-5{ }^{\circ} \mathrm{C}\right) ; 2$ - ice, high temperature of ice surface $\left(>-5{ }^{\circ} \mathrm{C}\right) ; 3$ - wet road, high water film $(>1 \mathrm{~mm}) ; 4$ - wet road, small water film $(<1 \mathrm{~mm}) ; 5-$ dry road
Comparison of predicted and statistical values of a tyreroad friction coefficient

\begin{tabular}{ccc}
\hline Type of road & $\begin{array}{c}\text { Predicted } \\
\text { value }\end{array}$ & $\begin{array}{c}\text { Mean statistical } \\
\text { value and } 95 \%- \\
\text { confidence interval }\end{array}$ \\
\hline $\begin{array}{c}\text { Dry asphalt } \\
\text { concrete }\end{array}$ & 0.846 & $\begin{array}{c}\mu_{\text {mean }}=0,8503 \\
{[0.7631,0.9375]}\end{array}$ \\
\hline Wet asphalt & $0.530 \ldots 0.570$ & $\begin{array}{c}\mu_{\text {mean }}=0,5764 \\
\text { concrete }\end{array}$ \\
\hline
\end{tabular}

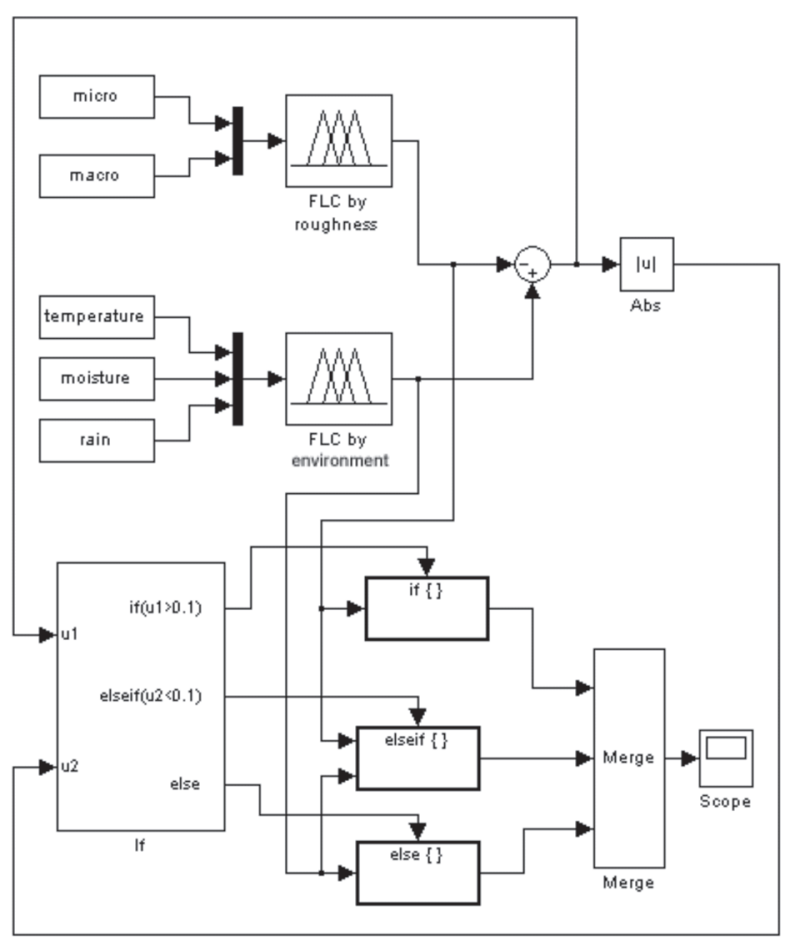

Fig 4. MATLAB-structure for simulation of road identification algorithm

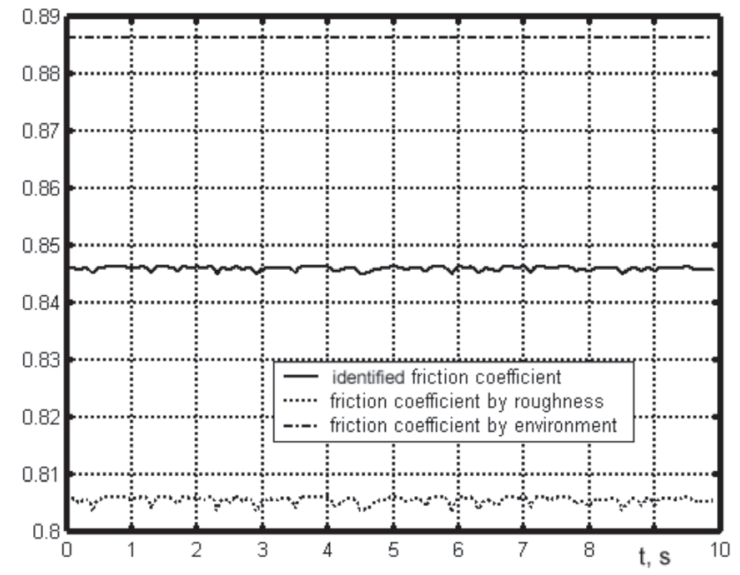

Fig 5. Example of road identification: dry asphalt concrete road by $10{ }^{\circ} \mathrm{C}$ and $60 \%$ of moisture 


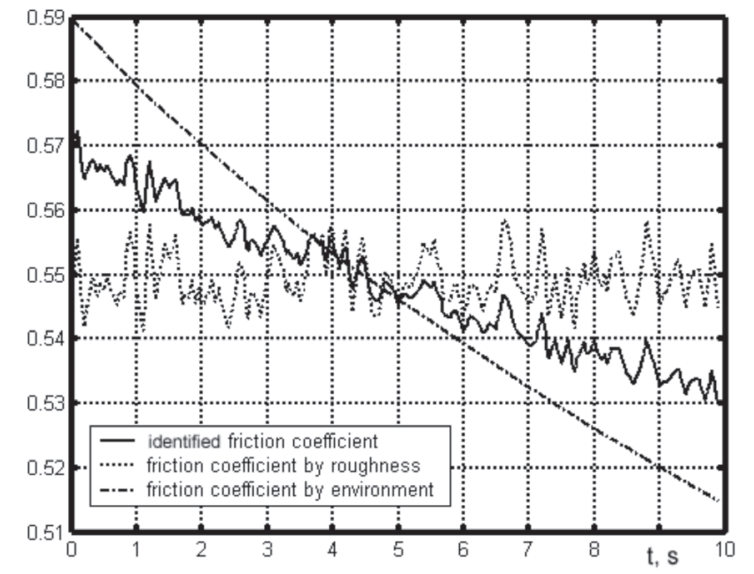

Fig 6. Example of road identification: wet asphalt concrete road by $10{ }^{\circ} \mathrm{C}, 60 \%$ of moisture and rain intensity from 0,7 to 0,8 during $t=10 \mathrm{~s}$

It should be pointed out that the developed strategy can be used not only in traditional algorithms of active safety systems. The proposed variant of road identification would be appropriate for use in systems with intelligent functions. This issue is further discussed.

\section{Application of road identification for active safety systems with pre-extreme control}

Most of up-to-date algorithms for active safety systems are based on the slip control that is well described in many fundamental works [13]. These systems trace the optimal area of the wheel rolling along $s$-axis, as applied to $m(s)$-curves from Fig 1.

The safety system with a slip-controller assesses kinematic parameters of a wheel, resulting in a number of negative moments:

- Stringent requirements to system adaptability because of possible drift of optimal control area under the effect of many factors: maneuver velocity, wheel loading, side slip, contact temperature et al.

- Insufficient accuracy of wheel slip definition owing to the absence of the sensors for real vehicle velocity

- Sensitivity of control process to high response time of a brake system; it is of value for heavyduty trucks, buses and road trains with the air operated brake drives.

To partially overcome these factors the strategy of pre-extreme control for wheel rolling can be proposed [11]. Figure 7 shows the structure of pre-extreme active safety system realizing the prediction of the optimal area for tyre grip. This system computes current parameters of tyre-road interaction $\left(s, \mu_{x}, \mu_{y}\right)$ with the data obtained from on-board sensors and

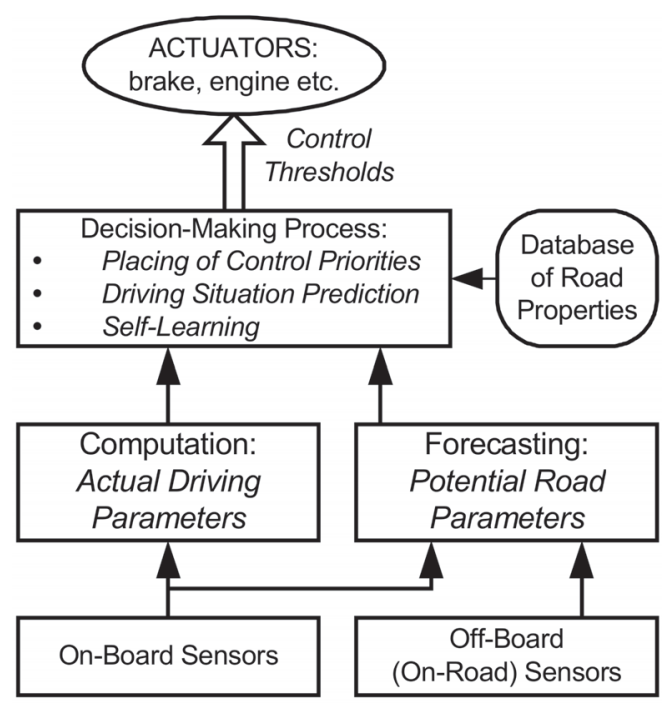

Fig 7. The structure of pre-extreme active safety system

predicts the potential area for maximal value of a tyreroad friction coefficient (parameter $\mu^{p}$ from Fig 1). The process of prediction uses fuzzy control for road identification.

The eventual rating of current driving conditions is in progress with regard to the dynamical mode of vehicle operation, operational characteristics of a suspension and the information from off-road sensors and external sources like the navigation systems and automated highway systems. Further the system generates preventive, pre-extreme control thresholds for actuators from the analysis of actual and potential parameters of driving. The work [12] contains more detailed description of such active safety system. Thus the main control parameters in a pre-extreme active safety system are variables related to the tyre-road friction coefficient. For the evaluation parameter for the selection of the control thresholds the safety coefficient

$$
k_{s}=1-\left(\mu_{x} / \mu^{P}\right)
$$

can be used [10]. In absence of a wheel forward movement the maximum potential of active safety takes place and $k_{s}=1$, on critical limit reaching the potential is depleted and $k_{s}=0$.

For the purposes of illustration MATLAB simulation of an anti-lock braking system with a pre-extreme algorithm and road identification was developed for a city bus with $10 \mathrm{t}$ fully loaded mass and a pneumatic brake drive (analogue: bus MAZ-106 manufactured by Automotive Plant Minsk). The models of a real brake drive and brake gears were fed into a system to take into account the response time of actuators and hysteresis losses in addition. The detailed description of a full vehicle model is not incorporated into this paper; therefore it makes sense to 
mention the main stages in the algorithm development.

During simulation procedure the foregoing variable $k_{s}$ is the performance index for a control process. The task of ABS controller is to hold $k_{s}$-value no more than $0,3 \ldots 0,4$ by optimum $k_{s} \rightarrow 0$. This decision allows simultaneously to ensure the high brake efficiency (no less than $75 \%$ from $\mu_{x}$-maximum in accordance with the normative requirements of vehicle braking) as well as the wheel rolling into stable slipping area.

The algorithm of road identification from Fig 4 provides for the calculation of a potential tyre grip coefficient $\mu^{P}$. To estimate the current value of a coefficient of longitudinal force $\mu_{x}$ the following single wheel model by braking has been used [1]:

$$
\begin{aligned}
& F \mu_{x}=\frac{1}{V_{s}}\left(N_{w}-N_{\text {hys }}-N_{m}\right)= \\
& \frac{1}{V_{s}}\left(m \cdot V \frac{d V}{d t}-\omega\left(M_{b r}-J \frac{d \omega}{d t}\right)-N_{\text {hys }}\right)
\end{aligned}
$$

where $V_{s}$ is the wheel slip velocity, $m$ is the weight reduced to a vehicle wheel, $M_{b r}$ is the brake torque of the brake gear, $\omega$ is angular velocity of a wheel, $V$ is the vehicle velocity, $J$ is the moment inertia of a wheel, $N_{w}$ is the wheel work in time unit, $N_{m}$ is dissipation taking into account the maneuver, $N_{\text {hys }}$ is dissipation power from tire hysteresis losses as a function of loading frequency $v$ and tire damping properties $k_{\mathrm{V}}$ tire pressure $p$ and temperature $T$, and also road properties defined by amplitude $A_{r}$ and wavelength of road roughness $L_{r}$ :

$$
N_{\text {hys }}=f\left(v, k_{V}, p, T, A_{r}, L_{r}\right) .
$$

Figure 8 gives an example of ABS diagrams by braking on a rolled asphalt concrete road, $17 \ldots 18^{\circ} \mathrm{C}$ of ambient air temperature, $80 \%$ of moisture, and 0,6 of rain intensity.

Since the task of simulation is only the approbation of the developed methods rather than the particular comparison of various ABS algorithms, the following conclusions can be made from the analysis of the simulation results:

- The peak values of wheel slip come to $s=0,4$ on an ice-covered and wet road by mean effective range in $0,06 \ldots 0,23$. Moreover, the momentary wheel blocking during the control process took no place, as differentiated from the standard algorithm with a slip controller realized in real ABS for the city bus under study.

- The maximal operational frequency of preextreme ABS averages between 4,0 and 5,5
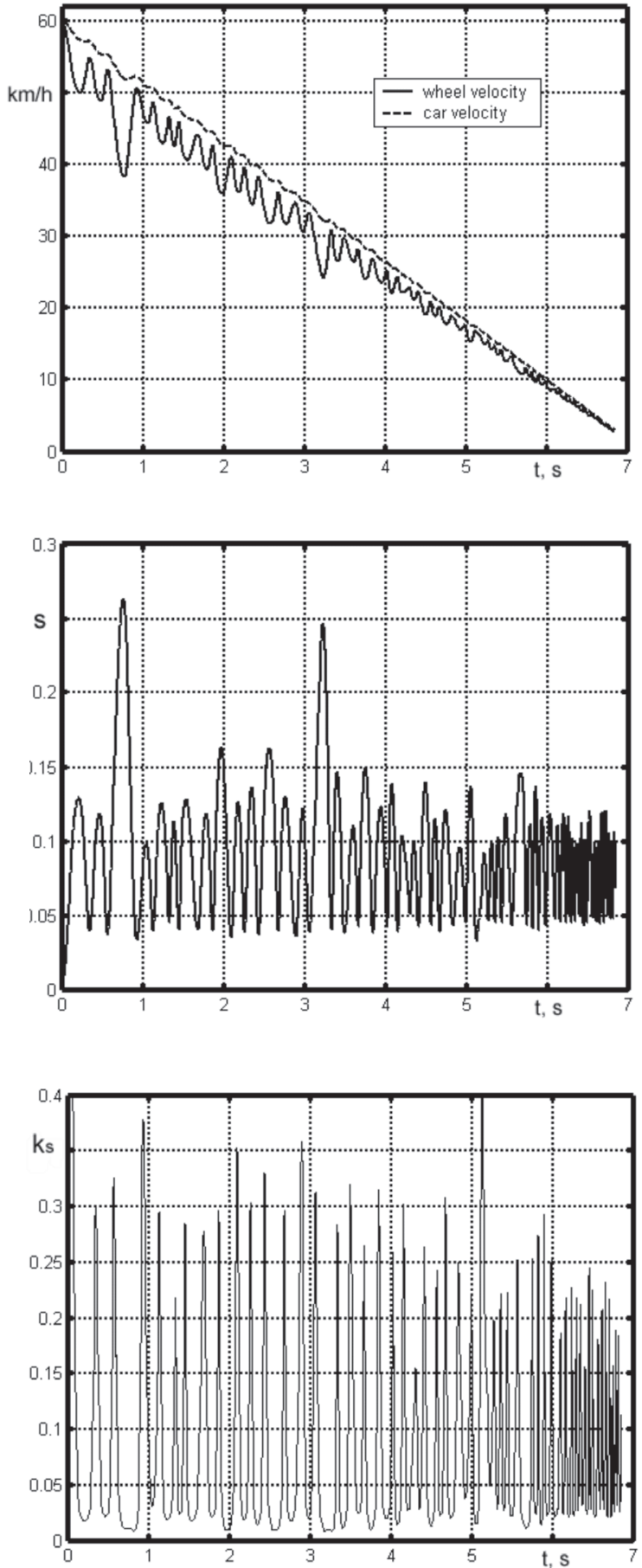

Fig 8. Example of simulation diagrams (rear wheel) for ABS braking

$\mathrm{Hz}$ depends on a road surface; the installed pneumatic brake drive can hold working frequency up to $8 \mathrm{~Hz}$.

- By braking on "mixt" road (various coefficient of friction for left and right wheels) the preextreme ABS ensured the brake distance reduction up to $12 \%$ in comparison with $8 \%$ for $\mathrm{ABS}$ with a slip controller; the effective 
range of wheel slip covers $0,10 \ldots 0,13$ at that.

Thus, the sufficient preliminary verification has been performed both for the proposed method of road identification and for the pre-extreme active safety control with forecasting procedures.

\section{Conclusion}

The paper proposed a procedure for the identification of road properties. This procedure is based on fuzzy logic methods and can be used in the algorithms of active safety systems. For the estimation of a tyre-road friction coefficient it makes sense simultaneously to apply the fuzzy controllers with the roughness parameters as input variables as well as with environmental conditions. It should be pointed out that the developed approaches need the appropriated offboard sensors and the vehicle itself must be a subject of Intelligent Transportation System.

The further development of the problems stated in this paper involves the investigation of the processes occurred at tyre-road interaction in pre-extreme area of dependence 'specific tyre forces - wheel slip'. This problem lies at the interfaces between the automatic control, tribology and vehicle dynamics and is of immediate interest to perspective researches.

\section{References}

1. Boutylin, V.; Lepeshko, J.; Ivanov, V. About Interrelation between the Tire Grip Properties and the Wheel Sliding. SAE Technical Paper Series. Warrendale: SAE, 2001, No 2001-01-3338, 5 p.

2. Cragelsky, I. V.; Mikhin, N. M. Machine Friction Units. (Узлы трения машин). Moscow: Mashinostroenie, 1984. 280 p. (in Russian).

3. Eichhorn, U. Reibwert zwischen Reifen und Fahrbahn - Einflussgrössen und Erkennung. Düsseldorf: VDIVerlag, 1994. $140 \mathrm{p}$.

4. Fischlein, H.; Gnadler, R.; Unrau, H.-J. Der Einfluss der Fahrbahnoberflächenstruktur auf das Kraftschlussverhalten von Pkw-Reifen bei trockener und nasser Fahrbahn. Automobiltechnische Zeitschrift, Bd. 103, Nr. 10, 2001, p. 950-962.

5. Germann, S.; Wurtenberger, M.; Daiß, A. Monitoring of the Friction Coefficient between Tyre and Road Surface. In: Proc. of $3^{\text {rd }}$ IEEE Conference on Control Application. Glasgow: IEEE, 1994, p. 613-618.

6. Gustaffson, F. Slip-Based Tire-Road Friction Estimation. Automatica, Vol 33, No 6, 1997, p. 1087-1099.

7. Herrtwich, R. Communication-Based Safety Applications. In: Proc. of Barcelona 2004 FISITA World Automotive Congress. Barcelona: STA, 2004, No F2004I027. $4 \mathrm{p}$.

8. Hong, H. J.; Jo, H. Y. Prediction of Friction Between
Tire and Road Using Powertrain Model. In: Proc. of AVEC '98 Symposium. Nagoya: AVEC, 1998, p. 135140.

9. Ivanov, V. G. Pre-Extreme Control in Intelligent Systems of Automotive Active Safety (Доэкстремальное управление в интеллектуальных системах активной безопасности автомобиля). Minsk: Publishing of Belarusian National Technical University, Minsk, 2004. 210 p. (in Russian).

10. Ivanov, V.; Boutylin, V.; Lepeshko, J. The Strategy for Control of Automotive Active Safety. In: FISITA 2002 Proceedings. Helsinki: SATL, 2002. 20 p.

11. Ivanov, V.; Vysotsky, M.; Boutylin, V.; Lepeshko, J. The Theoretical Concepts for Pre-Extreme ABS. SAE Technical Paper Series. Warrendale: SAE, 2002, No 2002-01$2185.8 \mathrm{p}$.

12. Ivanov, V.; Siakhovich, U. Theoretical Aspects of Automotive Active Safety: Results and Evolution. In: FISITA 2004 Proceedings. Barcelona: STA, 2004. 18 p.

13. Kiencke, U.; Nielsen, L. Automotive Control Systems. Heidelberg: Springer, 2000. 416 p.

14. Liu, C.; Peng, H. Road Friction Coefficient Estimation for Vehicle Path Prediction. Vehicle System Dynamics Vol 25, 1996, p. 413-425.

15. Ninomiya, J.; Minakawa, M.; Orimoto, Yu.; Nakahara, J. Measurement Technique of the Force Transmitted from Road Surface to Tire During Actual Driving, and its Application. In: Proc. of AVEC '98 Symposium. Nagoya: AVEC, 1998, No 9836662, p. 225-230.

16. Nüssle, M.; Gnadler, R. Messeinrictung zur Bestimmung von Reifenkennlinien im Fahrbetrieb. $A T Z$ Automobiltechnische Zeitschrift, Bd. 103, 2001, p. 628 634.

17. Pal, C.; Hagiwara, I.; Morishita, S. Inoue, H. Application of Neural Networks in Real Time Identification of Dynamic Structural Response and Prediction of RoadFriction Coefficient from Steady State Automobile Response. In: Proc. of AVEC ' 94 Symposium. Tsukuba: AVEC, 1994, No 9438826. 8 p.

18. Pasterkamp, W. R.; Pacejka, H. B. Application of Neural Networks in the Estimation of Tire/Road Friction Using the Tire as Sensor. SAE Technical Paper Series. Warrendale: SAE,1997, No 971122. 7 p.

19. Ray, L. R. Nonlinear State and Tire Force Estimation for Advanced Vehicle Control. IEEE Transactions on Control Systems Technology, Vol 3, No 1, 1995, p. 117 124.

20. Ray, L. R. Nonlinear Tire Force Estimation and Road Friction Identification: Simulation and Experiments. Automatica, Vol 33, 1997, p. 1819-1833.

21. Siegert, E., von Glasner, E.-C., Geissler, H. Fahrsicherheitssysteme / Bosch. Wiesbaden: Vieweg, 1998. 250 p.

22. Stumpf, H. W. Mathematical modeling of tire characteristic properties. In: Proceedings of $8^{\text {th }}$ European Automotive Congress. Bratislava: SAITS, 2001, p. $257-$ 268. 
23. Weiblen, W.; Kockelmann, H.; Burkard, H. Evaluation of Different Designs of Wheel Force Transducers (Part II plus Extensions). In: Proc. of JSAE Spring Convention. Tokyo: JSAE, paper 20005305, 2000. 4 p.

24. Wu, W.; Yoon, Y.-S. A Study of Road Identification for Anti-Lock Brake Systems Equipped only with Wheel Speed Sensors. In: Proc. of Seoul 2000 FISITA World Automotive Congress. Seoul: KSAE, 2000. F2000G335, $3 \mathrm{p}$.

25. Yi, J.; Alvarez, L.; Horowitz, R. Adaptive Emergency Braking Control With Underestimation of Friction Coefficient. IEEE Transactions on Control Systems Technology, Vol 10, No 3, 2002. p. 381-392.

26. Yi, K.; Jeong, T. Observer Based Estimation of TireRoad Friction for Collision Warning Algorithm Adaptation. JSME International Journal, Vol 41, 1998. p. 116124. 